\title{
NOTE
}

\section{Preferences of invasive lionfish and native grouper between congeneric prey fishes}

\author{
Tye L. Kindinger*, Emily R. Anderson \\ Department of Integrative Biology, Oregon State University, Corvallis, OR 97331, USA
}

\begin{abstract}
To gain insight about how an invasive predator may influence native prey, we performed a series of experiments in aquaria to characterize and compare the prey preferences of the invasive red lionfish Pterois volitans and an ecologically similar native mesopredator, the graysby grouper Cephalopholis cruentata. Preference for native congeneric fishes, the fairy basslet Gramma loreto and blackcap basslet G. melacara, were tested. We observed behavior of predators in response to 2 individual prey consisting of cross-factored combinations of species (fairy and blackcap basslets) and size (small and large). Upon initial exposure to prey, lionfish first hunted fairy basslet and graysby first hunted blackcap basslet, with both predators initially preferring large over small fish. Overall behavior (quantified from the entire duration of observation) indicated both predators lacked a preference between basslet species based on total number of strikes and hunting time. Despite essentially identical size ranges of predators studied, graysby overall preferred large basslet across all graysby sizes, whereas the overall preference of lionfish between prey size varied with lionfish size. Importantly, the initial preferences of predators were likely least affected by the unnatural setting in aquaria. By preferentially consuming the lesspreferred prey species of native graysby or by increasing predation on larger basslets, invasive lionfish may enhance coexistence between basslet species or among basslet sizes within local populations structured according to a size hierarchy. Alternatively, increased consumption of basslets may deplete local basslet populations, especially if lionfish exhibit prey switching behavior.
\end{abstract}

KEY WORDS: Predation · Prey preference - Invasive species · Coral reefs · Lionfish · Grouper • Basslets

\section{INTRODUCTION}

Invasive predators typically have effects on native prey that are more severe than those of native predators (Salo et al. 2007) and can cause substantial declines in populations of native species (Pitt \& Witmer 2007). These predators often have generalized diets and, in extreme cases, can drive native species to local or global extinction (Clavero \& García-Berthou 2005). Therefore, accurately predicting the effects of invasive predators on native prey populations and

${ }^{*}$ Corresponding author: kindingt@science.oregonstate.edu communities is important for informing management and conservation strategies.

A key mechanism underlying predatory effects is prey preference. Predators may have a preferred prey which is disproportionately consumed, or they may exhibit prey switching behavior (sensu Murdoch 1969) where the predator switches to other available prey once the preferred prey becomes rare. Further, the combination of native and invasive predation may result in enhanced depletion of a single prey species if both predators have a preferred prey in

() The authors 2016. Open Access under Creative Commons by Attribution Licence. Use, distribution and reproduction are unrestricted. Authors and original publication must be credited. 
common. If predators differ in prey preference, predation may also be enhanced as the invasive predator consumes the less-preferred prey of the native predator. Switching behavior exhibited by an invasive predator could ultimately lead to the extinction of native prey (e.g. Savidge 1987). Overall, understanding the prey preference of an invasive predator and comparing it to that of a native predator can reveal potential mechanisms underlying the overall effects of an invasion on native communities.

By performing a series of experiments, we characterized the prey preference of an invasive marine predator, the Pacific red lionfish Pterois volitans, and compared this preference to that of an ecologically similar mesopredator that is native throughout the Atlantic, the graysby grouper Cephalopholis cruentata. Invasive lionfish are commonly found on coral reefs throughout the tropical and subtropical Western Atlantic and greater Caribbean region (Schofield 2010) and, like the native graysby, are considered to be generalist predators (e.g. Morris \& Akins 2009). As a voracious predator, invasive lionfish can cause large reductions in the abundance of small native fishes and declines in species richness at scales that range from smaller patch reefs (e.g. Albins \& Hixon 2008) to large coral reefs (Albins 2015).

Marine piscivores often preferentially distinguish among prey by species (e.g. Almany et al. 2007) or by size (e.g. Floeter \& Temming 2003). We hypothesized that native graysby and invasive lionfish have similar prey preferences, because they are both generalist mesopredators. We predicted that neither predator would display a strong preference between 2 congeneric prey species, and that both would exhibit shifts in preference from smaller- to larger-sized prey with increasing predator size, because both graysby and lionfish are gape-limited predators.

\section{MATERIALS AND METHODS}

\section{Study area and fish collection}

We conducted this study during August 2014 at the Cape Eleuthera Institute on Eleuthera, the Bahamas, where we investigated the preference of predators for 2 native coral-reef fishes, the fairy basslet Gramma loreto and blackcap basslet G. melacara. These congeners are popular aquarium fishes that differ in appearance primarily by coloration (Fig. S1 in the Supplement at www.int-res.com/articles/suppl/m558 p247_supp.pdf) and are commonly found under ledges (rock overhangs) throughout Caribbean reefs
(Böhlke \& Randall 1963, Starck et al. 1978). SCUBA divers collected basslets from reefs in the Exuma Sound at maximum depths of $15 \mathrm{~m}$ with small aquarium hand nets and the fish anesthetic quinaldine. We collected graysby and lionfish from shallow patch reefs ( $<5 \mathrm{~m}$ deep) in Rock Sound using, respectively, hand fishing lines while snorkeling and hand nets on SCUBA. We collected 15 lionfish ranging in size from 10.2 to $20.9 \mathrm{~cm}$ total length (TL) and 15 graysby with a size range of 10.0 to $20.3 \mathrm{~cm}$ TL. All fish were maintained in outdoor tanks with continuous flowthrough saltwater systems and fed daily; predators were fed live silverside fish and basslets were fed live brine shrimp (Artemia sp.).

\section{Experimental design}

We conducted all experimental trials in 50 gallon (ca. $190 \mathrm{l})$ acrylic aquarium tanks $(91.5 \times 38 \times 51 \mathrm{~cm})$ with continuous flow-through seawater systems. Food was withheld from predators for $24 \mathrm{~h}$ prior to observation to ensure predator response to the presence of prey. Tanks were divided in half with a removable central barrier of solid aluminum (Fig. 1). We released a single predator into one side of the tank and placed 2 basslets in the other side. Basslets were held in identical small glass containers ( $500 \mathrm{ml})$ with mesh covers (1 basslet per container) positioned in each corner of the tank. These prey containers ensured that predators were able to receive both visual and chemical cues from basslets, but could neither make physical contact nor consume any basslets.

To determine whether the preference of predators for basslets was driven by basslet species (fairy and blackcap) or basslet size (small and large: 1.7-2.5 and $3.5-5.2 \mathrm{~cm} \mathrm{TL}$, respectively) we presented pairs of basslets in cross-factored combinations of the 2 variables, resulting in the following treatments: (1) small fairy and large fairy, (2) small blackcap and large blackcap, (3) small fairy and small blackcap, (4) large fairy and large blackcap, (5) small fairy and large blackcap, and (6) large fairy and small blackcap. In addition to randomizing the order of basslet treatments presented to each predator, we also randomized the corner of the tank basslets were placed in every time a treatment was presented.

Once the predator and basslets were in their respective sides of the tank, we allowed them to acclimate for $20 \mathrm{~min}$, after which we removed the central barrier and observed the predator's behavior for $10 \mathrm{~min}$. Observations were performed either in per- 


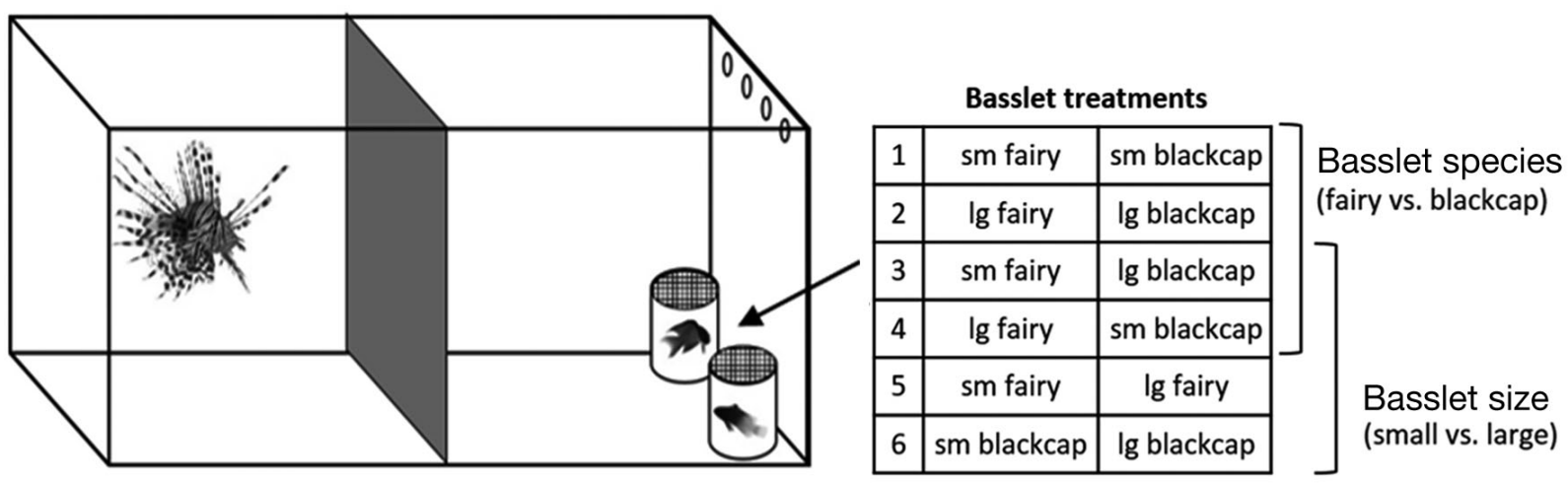

Fig. 1. Experimental tank setup (left), consisting of a 50 gallon (ca. 190 l) acrylic aquarium tank, divided by a removable aluminum central barrier separating basslets in $\sim 500 \mathrm{ml}$ glass containers with mesh covers from a predator (lionfish shown here). After a 20 min acclimation period, the central barrier was removed and predator behavior was observed in response to randomized combinations of individual basslets randomly placed in glass containers. Basslet treatments (right) consisted of basslet species (fairy and blackcap) cross-factored with basslet size (small: 1.7 to $2.5 \mathrm{~cm}$ TL; large: 3.5 to $5.2 \mathrm{~cm}$ TL) to determine whether the preference of predators was driven by either variable

son (74 lionfish trials; 73 graysby trials) or filmed with a digital video camera (16 lionfish trials; 17 graysby trials) positioned outside of the tank. During each 10 min trial, we recorded (1) which basslet the predator hunted first (initial hunting preference); (2) the number of times the predator's mouth made physical contact with each glass container (number of strikes); and (3) the amount of time the predator hunted each basslet (hunting time). We defined the hunting behavior of lionfish as occurring when an individual directly faced a basslet with flared pectoral fins and/or blew pulsed jets of water towards a basslet (Cure et al. 2012). We characterized graysby hunting behavior as occurring when an individual positioned itself near a basslet $(<10 \mathrm{~cm}$ in this experiment) while directly facing the basslet (Webster 2004).

At the conclusion of the $10 \mathrm{~min}$ trial, we separated the predator from the basslets and placed the central barrier back in the tank. A new combination of basslets were placed in the glass containers, and all fish were allowed to acclimate for $20 \mathrm{~min}$ before removing the barrier and observing predator response for another $10 \mathrm{~min}$. This procedure was repeated until all 6 basslet treatments had been presented to each predator in random order.

\section{Statistical analyses}

When testing for significant differences in predator response between fairy versus blackcap basslets, we analyzed only the 4 treatments where predators were presented with 2 different basslet species (lionfish: $\mathrm{n}=11$; graysby: $\mathrm{n}=11$ ). Similarly, we analyzed the 4 treatments where we presented predators with 2 basslets differing in size (small versus large) when comparing predator response between basslet sizes (lionfish: $\mathrm{n}=13$, graysby: $\mathrm{n}=12$ ). If a predator did not display any predatory behavior during any of the 4 treatments described in the treatment groupings above, then the individual was dropped from that respective group prior to analysis (resulting in the final sample sizes reported above).

To test whether initial hunting preferences between basslet species (fairy and blackcap) and basslet sizes (small and large) significantly differed between predators (lionfish and graysby) and/or among predator sizes (continuous variables), we fitted generalized estimation equations (GEEs) with binomial distributions and exchangeable correlation structures. GEEs are an extension to the generalized linear model approach that allow for correlations between observations from the same subject, thus allowing us to account for repeated measures. We fitted a full model with an interaction between predators and predator size, and then compared the model fit to that of the reduced additive model by calculating quasilikelihood values under the independence model criterion (QIC; Pan 2001). If the initial hunting preference significantly varied between predators, we then performed a post-hoc McNemar test with a continuity correction for lionfish and graysby (separately) to test whether each predator had a significant initial preference.

We fitted full GEEs with Poisson distributions and exchangeable correlation structures to test whether the number of strikes and hunting time of predators significantly depended on a 3-way interaction among 


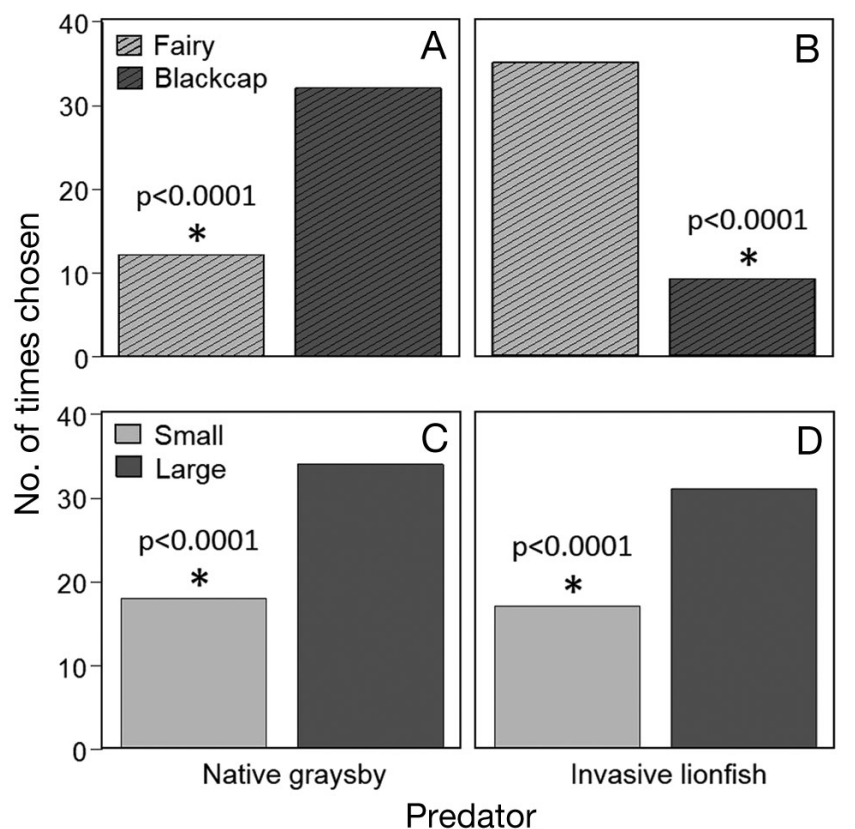

Fig. 2. Initial hunting preference of (A) native graysby and (B) invasive lionfish between fairy versus blackcap basslets ( $\mathrm{n}=11$ graysby, $\mathrm{n}=11$ lionfish), and preference of (C) graysby and (D) lionfish between small versus large basslets ( $\mathrm{n}=$ 12 graysby, $\mathrm{n}=13$ lionfish). Bars represent the total number of times that each predator initially hunted each basslet during treatments consisting of 2 different basslet species $(n=4$ per individual predator) and 2 different basslet sizes ( $\mathrm{n}=4$ per individual predator). Asterisks and p-values indicate significant differences in predator response between basslet species and size based on post-hoc McNemar tests

the type of predator, predator size, and basslet species. We compared the full and reduced additive GEEs with QIC. If the 3-way interaction was significant, we fitted GEEs for lionfish and graysby separately to determine whether each predator's response significantly differed among predator size and/or basslet species (or an interaction between the 2). Again, final models (full versus reduced) were selected for each predator based on QIC values. We repeated this entire process, but with basslet size instead of basslet species as an explanatory variable in all the GEEs. All statistical analyses were conducted using R version 3.1.2 (R Core Team 2014) with the associated packages geepack (Halekoh et al. 2006) and MESS (Ekstrom 2014).

\section{RESULTS}

Invasive lionfish and native graysby exhibited clear initial hunting preferences for basslet species that significantly differed between predators (Fig. 2A,B; GEE,
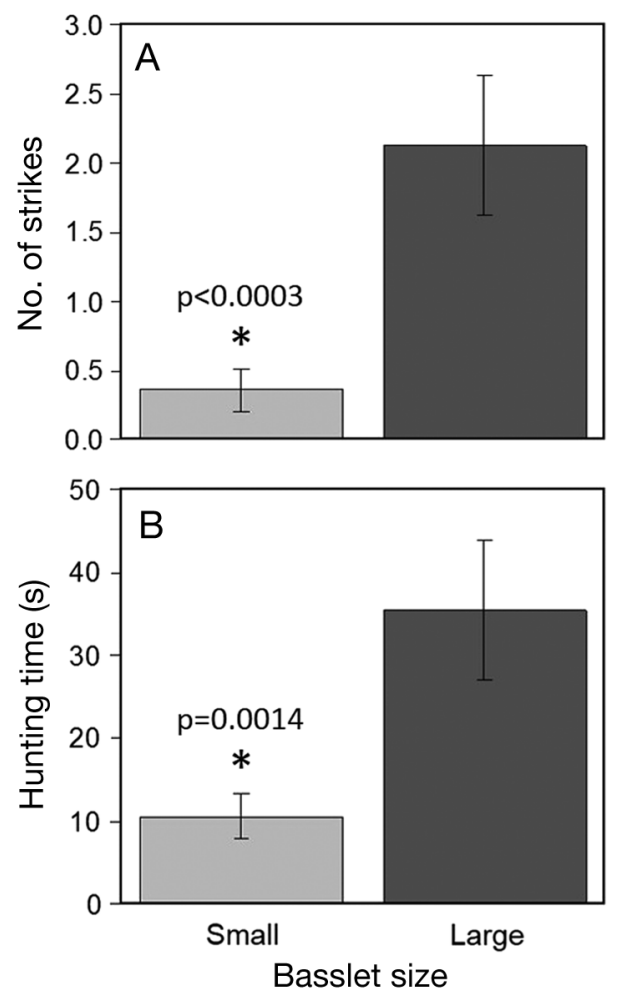

Fig. 3. Mean $( \pm \mathrm{SE})(\mathrm{A})$ number of strikes and (B) amount of time spent hunting by native graysby $(n=12)$ in response to small versus large basslets during treatments consisting of 2 different basslet sizes ( $\mathrm{n}=4$ per individual predator). Asterisks and p-values indicate significant differences in response between basslet sizes based on generalized estimation equations (GEEs)

Wald $\chi^{2}=25.5, \mathrm{p}<0.0001$ ), yet did not significantly differ among predator sizes (GEE, Wald $\chi^{2}=1.49, \mathrm{p}=$ 0.22). Upon initial exposure to both basslet species, lionfish first hunted fairy basslet significantly more often than blackcap basslet (McNemar test $\chi^{2}=96.01$, $\mathrm{p}<0.0001$ ), whereas graysby initially hunted blackcap basslet (McNemar test; $\chi^{2}=62.02, \mathrm{p}<0.0001$ ). However, these initial preferences were not maintained for the remainder of the observational periods. Across all predator sizes observed, there was no significant difference in the number of strikes or hunting time directed at each basslet species exhibited by either predator (Table S2 in the Supplement at www.intres.com/articles/suppl/m558p247_supp.pdf).

When testing the initial hunting preference between basslet sizes, we found that, despite the full GEE model having a lower QIC value than the reduced model (Table S1), the interaction between the predator species and predator size was not significant (GEE, Wald $\chi^{2}=2.60, \mathrm{p}=0.11$ ).

Initial preference between basslet sizes did not significantly differ between predator species (GEE, 


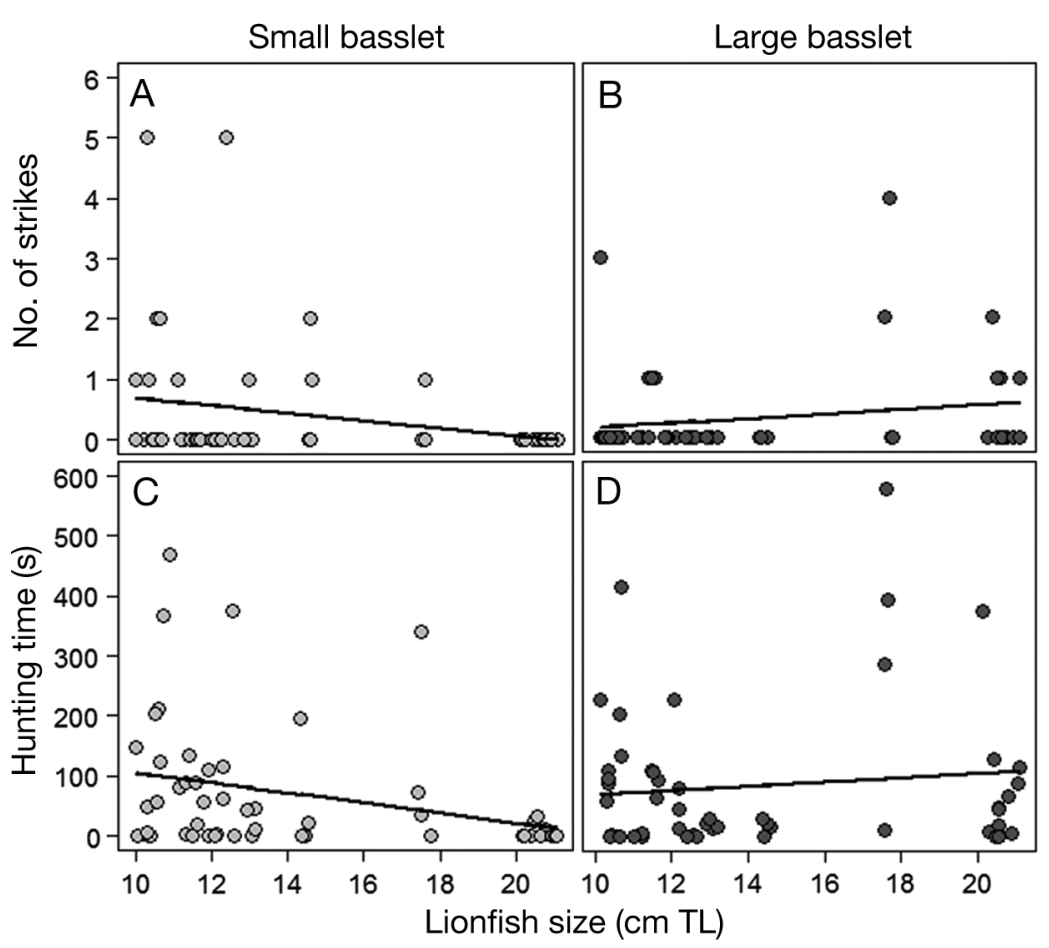

Fig. 4. Number of strikes by invasive lionfish $(n=13)$ throughout a range of lionfish sizes (cm TL) in response to (A) small and (B) large basslets, and amount of time spent hunting (C) small and (D) large basslets during treatments consisting of 2 different basslet sizes ( $\mathrm{n}=4$ per individual predator). Regression lines were calculated from models with significant interactions between lionfish size and basslet size

\section{DISCUSSION}

The distinctiveness hypothesis postulates that invasive predators are expected to have similar effects on prey species that are taxonomically and functionally similar (e.g. Ricciardi \& Atkinson 2004). Contrary to this prediction, we have provided evidence of an invasive marine predator having strong prey preferences that depend on both the species and size of prey upon initial exposure to a pair of congeneric coral-reef fishes. Lionfish first hunted fairy basslet more often than blackcap basslet, and initially preferred large over small fishes. In contrast, native graysby first hunted blackcap basslet, yet were consistent with lionfish in exhibiting an initial preference for large fish. Following these initial preferences, overall predatory behavior quantified from the entire duration of observations revealed that both the invasive and native predators hunted and struck about equally at both basslet species. In terms of overall preference between prey size, only the prefer-

Wald $\chi^{2}=2.57, \mathrm{p}=0.11$ ) nor across predator sizes (GEE, Wald $\chi^{2}=1.01, \mathrm{p}=0.31$ ). Both lionfish and graysby had a significant initial preference for large basslet (Fig. 2C,D; McNemar tests, $\chi^{2}=16.1$ and 29.0, respectively; $\mathrm{p}<0.0001$ for both predators). This preference for large basslet remained consistent for graysby in terms of both the overall number of strikes (Fig. 3A; GEE, Wald $\chi^{2}=13.19, \mathrm{p}<0.0003$ ) and hunting time (Fig. 3B, GEE, Wald $\chi^{2}=10.24, p=0.0014$ ). This preference was also maintained across all sizes of graysby tested (number of strikes: GEE, Wald $\chi^{2}=$ $0.65, \mathrm{p}=0.4202$; hunting time: GEE, Wald $\chi^{2}=0.01$, $\mathrm{p}=0.9433)$. In contrast, both the overall number of strikes and hunting time of lionfish depended on a significant interaction between the size of lionfish and basslet size (Fig. 4; number of strikes: GEE, Wald $\chi^{2}=8.42, \mathrm{p}=0.0037$; hunting time: GEE, Wald $\chi^{2}=11.53, \mathrm{p}<0.0007$ ). Predatory behavior directed at small basslet was greatest among smaller lionfish sizes, and gradually decreased with increasing lionfish size (Fig. 4A \& C). We found the opposite trend in response to large basslet, with increasing levels of predatory response as lionfish size increased (Fig. 4B \& D). ence of invasive lionfish varied with predator size. Native graysby preferred large fishes across all predator sizes, yet smaller lionfish preferred small basslets and larger lionfish preferred large basslets.

We also observed additional differences in behavior between predators in response to basslets. Graysby typically performed strikes at basslets in quick succession, striking the glass containers up to as many as 9 times in $3 \mathrm{~s}$. In contrast, there was a minimum of $2 \mathrm{~s}$ between individual lionfish strikes. We also observed lionfish more often than graysby switching between the two prey basslets within a single trial. A review of the trials we recorded with a digital camera revealed that lionfish switched between basslets a total of 31 times, whereas graysby switched only 6 times. More than half of the observed switches by lionfish seemed associated with basslet movement. Typically, immediately following the movement of a basslet in the glass container, the lionfish turned its attention to that basslet. None of the switches between basslets by graysby were associated with basslet movement.

Both in the experimental setting of this study and on natural reefs, recognition of basslet species by 
lionfish and graysby likely involves the use of visual and/or olfactory cues from prey (or combinations of both). Most reef fish have acute color vision (McFarland 1991), so these predators may be able to interpret the differences in coloration between fairy and blackcap basslets. Preferences for a prey species could also be explained by varying activity levels between basslets. Anecdotally, fairy basslet appeared to be more active in the glass containers compared to blackcap basslet in this study, and our observations of lionfish often switching between basslets when hunting seemingly in response to basslet movement further supports this hypothesis. Kindinger (2016) revealed that on coral reefs, fairy basslet were more aggressive than blackcap basslet, which may indicate fairy basslet are also more conspicuous in a natural setting.

The behavior of predators observed in this study suggests that invasive lionfish may have a slightly broader range of effects on basslets than native graysby, given that lionfish are seemingly more likely to hunt both small and large basslets, and even may exhibit switching behavior. However, the initial preferences of predators are of particular importance, because these observations were least likely to reflect the unnatural setting used in this study. Predators in aquaria were unable to consume prey fishes, and the glass containers with basslets seemed to deter predators. Once a predator struck at the glass, there were often few subsequent strikes for the remainder of a trial, although predators did continue to display hunting behavior. Therefore, if the initial observations of behavior are indicative of the true preferences of these predators, then the addition of invasive lionfish on reefs may promote coexistence between basslets by consuming the less-preferred species of the native predator. In contrast, invasive lionfish may enhance overall predation of larger basslets.

The combination of invasive and native predation likely results in complex interactions with basslets. Basslets are found distributed among ledge positions in local populations based on a size hierarchy (Webster \& Hixon 2000, Kindinger 2016). Under ledges, individuals compete both within and between species for feeding position, whereby larger individuals maintain coveted positions towards the fronts of ledges where the ability to obtain planktonic food is greatest. If both the invasive and native predators preferentially consume these larger fishes, the ability of smaller basslets to shift closer toward coveted feeding positions may increase. Interspecific competition between basslet species (Kindinger 2016) also may be altered by invasive lionfish via increased consumption of fairy basslet.

Alternatively, invasive lionfish may enhance predation of native basslets to the point where competition no longer exists within local populations. Indeed, previous field studies indicate that fairy basslet are faced with increased predation as a result of the addition of lionfish to native reefs (Ingeman \& Webster 2015), and invasive lionfish can even drive local populations of fairy basslet to extinction (Ingeman 2016, this Theme Section). In addition to these effects on fairy basslet, invasive lionfish may substantially affect both basslet species via elevated consumption rates of larger individuals. Over time, this increased consumption of larger size classes of prey could cause shifts in the overall size distribution of basslets, or potentially even influence population growth rates via preferential targeting of adult basslets that are reproductively mature. Additionally, the enhanced depletion of prey fishes could also have potential indirect effects on native predators (including graysby) via competition for food.

Our study demonstrates aspects of prey preference that are different and similar between invasive and native predators. As a result, invasive lionfish may at one extreme enhance coexistence by preferentially consuming the less-preferred prey species of the native predator or by enhancing preferential predation on larger, competitively-dominant basslets. At the other extreme, increased consumption of basslets by invasive lionfish may deplete local basslet populations, especially if lionfish exhibit switching behavior following the reduced availability of preferred prey. Determining how the combination of invasive and native predation will ultimately affect native prey populations and communities is imperative for accurately predicting the extent of impact from an invasion, which can inform management and conservation initiatives.

Acknowledgements. We thank M. Hixon for being our academic advisor, C. Benkwitt, A. Davis, A. Stringer, and L. Tuttle for assistance in the lab and field, and the staff members of the Cape Eleuthera Institute for logistical support. C. Benkwitt, A. Davis, M. Hixon, and L. Tuttle provided constructive reviews of the manuscript. This study was funded by a National Science Foundation (NSF) research grant to M. Hixon (OCE-12-33027) and an NSF Graduate Research Fellowship to T.L.K.

\section{LITERATURE CITED}

Albins MA (2015) Invasive Pacific lionfish Pterois volitans reduce abundance and species richness of native Bahamian coral-reef fishes. Mar Ecol Prog Ser 522:231-243 
Albins MA, Hixon MA (2008) Invasive Indo-Pacific lionfish Pterois volitans reduce recruitment of Atlantic coral-reef fishes. Mar Ecol Prog Ser 367:233-238

Almany GR, Peacock LF, Syms C, McCormick MI, Jones GP (2007) Predators target rare prey in coral reef fish assemblages. Oecologia 152:751-761

Böhlke JE, Randall JE (1963) The fishes of the western Atlantic serranoid genus Gramma. Proc Acad Nat Sci Philadelphia 115:33-52

Clavero M, García-Berthou E (2005) Invasive species are a leading cause of animal extinctions. Trends Ecol Evol 20: 110

Cure K, Benkwitt CE, Kindinger TL, Pickering EA, Pusack TJ, Mcllwain JL, Hixon MA (2012) Comparative behavior of red lionfish Pterois volitans on native Pacific versus invaded Atlantic coral reefs. Mar Ecol Prog Ser 467:181-192

Ekstrom C (2014) MESS: miscellaneous esoteric statistical scripts. R package version 3.1.3. http://CRAN.R-project. org/package=MESS

Floeter J, Temming A (2003) Explaining diet composition of North Sea cod (Gadus morhua): prey size preference versus prey availability. Can J Fish Aquat Sci 60:140-150

Halekoh U, Højsgaard S, Yan J (2006) The R package geepack for generalized estimating equations. J Stat Softw 15:1-11

Ingeman KE (2016) Lionfish cause increased mortality rates and drive extirpation of native prey. Mar Ecol Prog Ser 558:235-245

Ingeman KE, Webster MS (2015) Native prey mortality increases but remains density-dependent following lionfish invasion. Mar Ecol Prog Ser 531:241-252

Kindinger TL (2016) Symmetrical effects of interspecific competition on congeneric coral-reef fishes. Mar Ecol Prog Ser 555:1-11

McFarland W (1991) The visual world of coral reef fishes. In: Sale PF (ed) The ecology of fishes on coral reefs. Academic Press, San Diego, CA, p 16-38

Editorial responsibility: Ivan Nagelkerken, Adelaide, SA, Australia
Morris JA, Akins JL (2009) Feeding ecology of invasive lionfish (Pterois volitans) in the Bahamian archipelago. Environ Biol Fishes 86:389-398

Murdoch WW (1969) Switching in general predators: experiments on predator specificity and stability of prey populations. Ecol Monogr 39:335-354

Pan W (2001) Akaike's information criterion in generalized estimating equations. Biometrics 57:120-125

Pitt WC, Witmer GW (2007) Invasive predators: a synthesis of the past, present, and future. In: Elewa AM (ed) Predation in organisms. Springer, Heidelberg, p 265-293

R Core Team (2014) R: a language and environment for statistical computing. R Foundation for Statistical Computing, Vienna

Ricciardi A, Atkinson SK (2004) Distinctiveness magnifies the impact of biological invaders in aquatic ecosystems. Ecol Lett 7:781-784

Salo P, Korpimäki E, Banks PB, Nordström M, Dickman CR (2007) Alien predators are more dangerous than native predators to prey populations. Proc R Soc B 274: 1237-1243

Savidge JA (1987) Extinction of an island forest avifauna by an introduced snake. Ecology 68:660-668

Schofield PJ (2010) Update on geographic spread of invasive lionfishes (Pterois volitans [Linnaeus, 1758] and P. miles [Bennett, 1828]) in the Western North Atlantic Ocean, Caribbean Sea and Gulf of Mexico. Aquat Invasions 5: S117-S122

Starck II, Walter A, Colin PL (1978) Gramma linki: a new species of grammid fish from the tropical western Atlantic. Bull Mar Sci 28:146-152

- Webster MS (2004) Density dependence via intercohort competition in a coral-reef fish. Ecology 85:986-994

- Webster MS, Hixon MA (2000) Mechanisms and individual consequences of intraspecific competition in a coral-reef fish. Mar Ecol Prog Ser 196:187-194

Submitted: January 20, 2016; Accepted: July 11, 2016

Proofs received from author(s): August 22, 2016 